\title{
ONSHORE-OFFSHORE PATTERNS DURING THE ORDOVICIAN RADIATIONS: A WORLDWIDE ASSESSMENT
}

\author{
MILLER, Arnold I., Dept. of Geology (ML13), University of Cincinnati, \\ Cincinnati, OH 45221-0013
}

To understand the evolutionary significance of apparent temporal trends in global biotic diversity, it is important to delve beneath the umbrella of synoptic, global-scale compilations. Specifically, when evaluating a measurable increase or decrease on a global diversity curve, we must determine whether it reflects a transition that was truly global in scope and space-transcendent, or, alternatively, whether it is the manifestation of change associated with particular geographic or environmental regime(s).

Previous analyses of the Ordovician faunal radiations have suggested that an onshore-offshore environmental overprint was associated with the diversity increase: trilobite-dominated biotas, which were ubiquitous during the Cambrian, became progressively restricted to deepwater through the Ordovician as diversifying, articulate brachipod-dominated faunas came to dominate shallower, open marine settings. At the same time, a less rapid proliferation of mollusc-rich biotas enabled them to become particularly diverse in nearshore settings.

Additional analyses of diversification conducted for post-Paleozoic biotas have yielded onshore-offshore signals associated with diversification of a variety of taxa, suggesting the existence of a general evolutionary pattern associated with marine diversification that transcends taxonomy and time.

However, to date, evaluations of Ordovician onshore-offshore patterns have been based on data limited primarily to North America, and, thus, to the Paleozoic continent of Laurentia. Thus, it is reasonable to ask whether this pattern was unique to Laurentia, or whether diversification proceeded similarly in Ordovician seas around the world.

To analyze possible patterns of environmental and geographic selectivity associated with episodes of Ordovician diversification and extinction, I am currently compiling a database on the paleogeographic and paleoenvironmental distributions of Ordovician genera. Although this compilation is still in its infancy, preliminary analyses suggest that, in aggregate, paleoenvironmental patterns exhibited elsewhere are comparable to those recognized for Laurentia. However, the data remain scanty for many parts of the world; as the database grows, a province-by-province analysis of diversification patterns will be conducted. This analysis will not only permit determination of the degree to which onshore-onshore patterns transcended paleogeographic boundaries, but, more generally, will enable exploration of the relationship between local diversity trends and global-scale trends already documented for the Ordovician with synoptic data. 